\title{
The detection value of PD-L1 expression in biopsy specimens and surgical resection specimens in non-small cell lung cancer: a meta-analysis
}

\author{
Yang Wang", Junqi Wü, Jiajun Deng", Yunlang She, Chang Chen \\ Department of Thoracic Surgery, Shanghai Pulmonary Hospital, School of Medicine, Tongji University, Shanghai, China \\ Contributions: (I) Conception and design: C Chen, Y Wang; (II) Administrative support: C Chen; (III) Provision of study materials or patients: C \\ Chen; (IV) Collection and assembly of data: Y Wang, J Wu; (V) Data analysis and interpretation: Y Wang, J Wu, J Deng, Y She; (VI) Manuscript \\ writing: All authors; (VII) Final approval of manuscript: All authors. \\ "These authors contributed equally to this work. \\ Correspondence to: Chang Chen, MD, PhD; Yunlang She, MD. Department of Thoracic Surgery, Shanghai Pulmonary Hospital, School of Medicine, \\ Tongji University, Shanghai 200433, China. Email: chenthoracic@163.com; langthoracic@tongji.edu.cn.
}

Background: The detection value of different types of specimens for programmed death ligand-1 (PD-L1) expression remains controversial. As such, the purpose of this meta-analysis was to compare the detection value of biopsy specimens and surgical resection specimens for PD-L1 expression in patients with non-small cell lung cancer (NSCLC).

Methods: PubMed and Web of Science were searched prior to December 2020 to identify studies that compared the detection value of biopsy specimens and surgical resection specimens for PD-L1 expression in NSCLC. Quality Assessment of Diagnostic Accuracy Studies (QUADAS)-2 scale was used to evaluate the quality of the literature included. The detection value of different types of specimens for PD-L1 expression was then assessed. Besides, the relative risk (RR) with 95\% CI were pooled using Review Manager 5.3 software and Stata 14.0 software.

Results: The meta-analysis involved 12 articles and included 877 patients. There was no significant difference in the detection rate of PD-L1 at the $1 \%$ cutoff between biopsy specimens and surgical resection specimens ( $\mathrm{RR}=0.89,95 \% \mathrm{CI}: 0.70-1.12, \mathrm{P}=0.33)$. However, there was a significant difference between two groups when the cutoff is $50 \%$ ( $R R=0.69,95 \% \mathrm{CI}: 0.58-0.83, \mathrm{P}<0.01)$. In addition, a subgroup analysis of the type of biopsy specimens and the PD-L1 qualitative immunohistochemistry (IHC) assays showed that the detection rate of PD-L1 in small biopsies and using the SP142 antibody were lower than in surgical specimens and using other antibodies for both the $1 \%$ and $50 \%$ cut-offs $(\mathrm{P}<0.01)$.

Conclusions: Current evidence suggests that caution must be taken when using biopsy specimens from patients with advanced NSCLC to evaluate PD-L1 status eligible for immunotherapy, additional biopsy specimens sampling may be needed to minimize the risk of tumor misclassification. In addition, PD-L1 qualitative IHC assays and the type of biopsy specimens related to PD-L1 expression detection.

Keywords: Biopsy; specimen; programmed cell death ligand-1 (PD-L1); non-small cell lung cancer (NSCLC)

Submitted Mar 27, 2021. Accepted for publication May 27, 2021.

doi: $10.21037 /$ jtd-21-543

View this article at: https://dx.doi.org/10.21037/jtd-21-543 


\section{Introduction}

Lung cancer is the second most common malignancy and the most common cause of cancer-related mortality worldwide, among which non-small cell lung cancer (NSCLC) accounts for more than $85 \%$ of cases $(1,2)$. Patients with NSCLC often have locally advanced tumor or distant metastases at the time of diagnosis. For these patients, surgical treatment can no longer achieve radical treatment. In recent years, immunotherapy, such as Programmed death-1 (PD-1) and its Programmed death ligand-1 (PD-L1), which hinder tumor proliferation by blocking inhibitory pathways is important progress in oncology and a new direction for tumor therapy (3). At present, several clinical studies have confirmed that blocking the interaction between PD-1/PD-L1 with monoclonal antibodies can effectively alleviate the progression of advanced NSCLC and significantly improve the survival time of patients (4-7).

PD-L1 immunohistochemistry (IHC) is used to select patients for immunotherapy. Currently, a variety of PD-1 inhibitory monoclonal antibodies are available for the treatment of NSCLC patients. Pembrolizumab is approved by the Food and Drug Administration (FDA) for first-line treatment in patients with tumors showing $\geq 50 \%$ tumoral staining for PD-L1 (8). With the development of clinical trials, Pembrolizumab has also received FDA approval for second-line treatment in patients with advanced NSCLC who have received one or more previous treatment regimen and who have a tumor proportion score of at least $1 \%$. KEYNOTE-010 showed that Pembrolizumab extended overall survival in patients with $\mathrm{PD}-\mathrm{L} 1$ positive tumor cells (PD-L1 $\geq 1 \%$ Cutoff) (6). In addition, Pembrolizumab significantly prolonged progression-free and overall survival in patients with advanced NSCLC and PD-L1 expression at least $50 \%$ of tumor cells based on the result from the KEYNOTE-001 and KEYNOTE-024 trial $(8,9)$.

However, the use of immune checkpoint inhibitors may potentially cause severe immune-related adverse events such as pneumonitis and endocrine diseases, and the expression level of PD-L1 in tumor cells is closely related to the degree of PD-1 blocking response in patients. Therefore, accurate detection of PD-L1 expression in tumor cells is an important link to guide the use of immune checkpoint inhibitors and predict the prognosis of patients (10-12). Recent clinical trials have found that the expression level of PD-L1 in tumor cells has a certain predictive value for NSCLC patients who can benefit from immunotherapy. However, the studies of Taube $e t$ al. and Rittmeyer et al. both reported that NSCLC patients with negative PD-L1 expression also can benefit from immunotherapy $(12,13)$. There may be a variety of reasons for this phenomenon: the biological complexity of newly discovered tumor-immune interactions, the heterogeneity of PD-L1 expression $(14,15)$. Despite these limitations, the most recent National Comprehensive Cancer Network guidelines also recommend that PD-L1 expression should be measured in all NSCLC patients who intend to undergo immunotherapy.

In 2016, Ilie et al. compared the detection value of PDL1 expression in tumor cells from biopsy specimens and surgical resection specimens of 160 NSCLC patients, and proposed for the first time that the different detection value of these two specimens might be a potential problem for the application of PD-L1 immunotherapy (16). Subsequently, $\mathrm{Li}$ et al. once again proved that the PD-L1 expression levels of tumor cells in biopsy specimens and surgical resection specimens were inconsistent, suggesting that the sensitivity of PD-L1 detection using biopsy specimens was lower and some NSCLC patients who could benefit from immunotherapy might be wrongly excluded (17). However, the studies of Munari et al. and Hernandez et al. both showed that biopsy specimens can replace surgical resection specimens for the detection of PD-L1 expression in tumor cells of NSCLC patients $(18,19)$. Given the two controversial views mentioned above, the purpose of this meta-analysis was to evaluated and analyzed the accuracy of PD-L1 expression level detection in biopsy specimens and surgical resection specimens of NSCLC patients from the perspective of evidence-based medicine.

We present the following article in accordance with the PRISMA reporting checklist (available at https://dx.doi. org/10.21037/jtd-21-543) (20).

\section{Methods}

\section{Search strategy}

A systematic literature search was conducted in PubMed and Web of Science databases from inception to December 2020. The Mesh terms included biopsy; cytologic; specimen; programmed cell death ligand-1 (PD-L1); and lung cancer.

\section{Study selection}

The criteria for inclusion were as follows: (I) patients who were diagnosed with NSCLC and accepted PD-L1 IHC; (II) diagnostic studies comparing biopsy specimens versus surgical resection specimens; (III) both biopsy specimens 


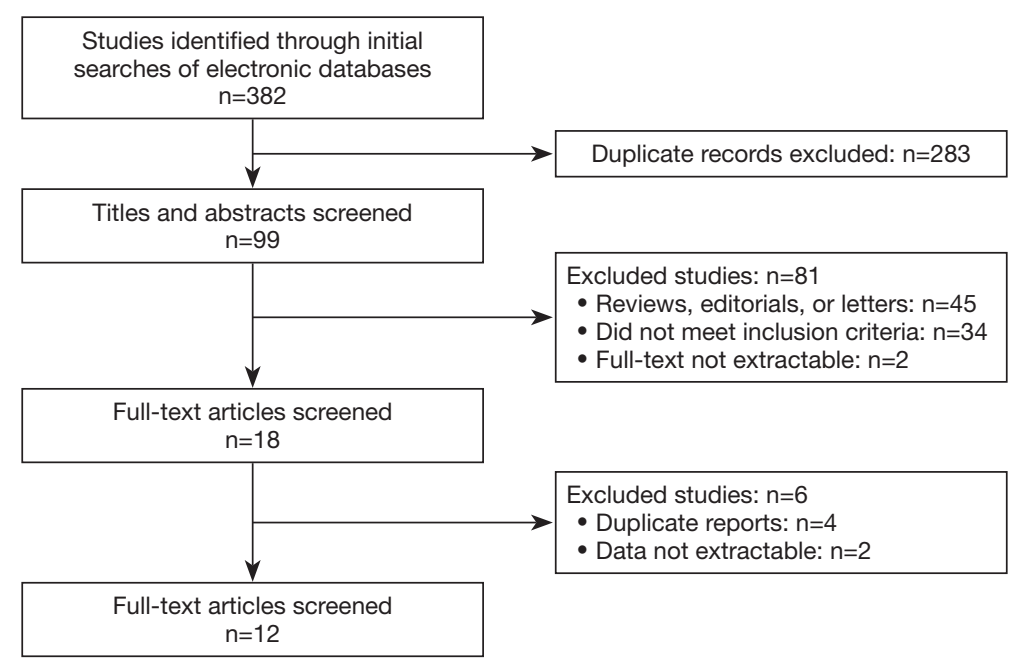

Figure 1 Flow diagram of study selection.

and surgical resection specimens should be available from the same patient; (IV) studies whose full texts were available and language was English. Studies were excluded based on the following criteria: publications with incomplete, useless data; review articles, meta-analysis, editorials, comments, letters, case reports, and animal experiments.

The selection of literatures was according to the process of reviewing titles, abstracts, and full texts. After preliminary screening of titles and abstracts, two independent researchers (J. D. and J. W.) assessed the full text to determine their conformity with the criteria. A consensus was achieved after discussion in case of disagreement.

\section{Data extraction and quality assessment}

Data from the included studies were extracted and summarized independently by two investigators (J. D. and J. W.) and then input into a Microsoft Excel (Microsoft Corporation, Redmond, WA, USA, 2019) database. The data extraction included the following: first author, time of publication; numbers of patients, median age, pathology or histology of cancer, PD-1/PD-L1 antibody, type of IHC specimens, and research type. Discrepancies in data extraction were resolved by consensus with a senior thoracic surgeon with professional-clinical knowledge (C. C.).

The quality of the included studies was independently evaluated according to the Quality Assessment of Diagnostic Accuracy Studies (QUADAS)-2 evaluation standard, which mainly consists of four parts: case selection, trial to be evaluated, gold standard, case flow, and progress (21).
All components were assessed for risk of bias, with the first three components also assessed for clinical suitability.

\section{Statistical analysis}

All mentioned analysis resorted to Review Manager 5.4 (Cochrane Collaboration, Oxford, UK) and Stata 14.0 (StataCorp, College Station, TX, USA). Relative risk (RR) with $95 \%$ confidence intervals $(95 \% \mathrm{CI})$ were calculated for dichotomous variables. Heterogeneity in the meta-analysis was evaluated with $\mathrm{I}^{2}$ test and Statistical heterogeneity was considered as $\mathrm{I}^{2}$ statistic greater than $50 \%$ (22). The fixedeffects model was used if the heterogeneity was acceptable ( $\mathrm{P}>0.10$, or $\mathrm{P} \leq 0.10$ but $\mathrm{I}^{2} \leq 50 \%$ ); Otherwise, the randomeffects model was used. Publication bias was checked by the funnel plots model and confirmed with Begg's and Egger's tests (23). The statistically significant $P$ value was set at $<0.05$.

\section{Results}

\section{Characteristics and quality assessment}

A total of 564 potential articles were retrieved from PubMed and Web of Science databases up to December 2020. Finally, a total of 12 original studies (16-19,24-31) involved 877 patients comparing the detection value of biopsy specimens and surgical resection specimens for PDL1 expression in NSCLC were obtained (Figure 1).

The baseline characteristics of the identified studies were summarized in Table 1. Except for the studies for which no 
Table 1 Basic characteristic of included studies

\begin{tabular}{|c|c|c|c|c|c|c|c|c|c|c|c|c|c|c|c|c|c|c|}
\hline \multirow{2}{*}{$\begin{array}{l}\text { Study (published } \\
\text { year) }\end{array}$} & \multirow[b]{2}{*}{ Country } & \multirow[b]{2}{*}{$\mathrm{N}$} & \multirow{2}{*}{$\begin{array}{l}\text { Average age } \\
{\text { [range }]^{\mathrm{a}}}^{\text {a }}\end{array}$} & \multirow[b]{2}{*}{$\mathrm{M} / \mathrm{F}$} & \multicolumn{4}{|c|}{ Pathological stage } & \multirow{2}{*}{$\begin{array}{c}\text { Histology } \\
\text { (SCC/ADC/NOS) }\end{array}$} & \multirow{2}{*}{$\begin{array}{l}\text { PD-L1 1HC } \\
\text { assays }\end{array}$} & \multicolumn{2}{|c|}{$P D-L 1 \geq 1 \%$} & \multicolumn{2}{|c|}{ PD-L1 $\geq 50 \%$} & \multirow{2}{*}{$\begin{array}{l}\text { Surgical resection } \\
\text { specimens }\end{array}$} & \multirow[b]{2}{*}{ Type of biopsy specimens } & \multirow[b]{2}{*}{ Biopsy modality } & \multirow[b]{2}{*}{ Study design } \\
\hline & & & & & 1 & $\|$ & III & IV & & & Biopsy specimens, n & $\begin{array}{l}\text { Surgical resection } \\
\text { specimens, } n\end{array}$ & Biopsy specimens, n & $\begin{array}{l}\text { Surgical resection } \\
\text { specimens, } n\end{array}$ & & & & \\
\hline Munari et al. (2018) & Italy & 55 & 71 [51-83] & $39 / 16$ & 37 & NR & NR & NR & $6 / 45 / 4$ & SP263 & NR & NR & 10 & 15 & Primary tumor & Cytologic specimens & FNA & $\mathrm{R}$ \\
\hline $\begin{array}{l}\text { Hernandez et al. } \\
\text { (2019) }\end{array}$ & USA & 38 & 68 [36-91] & NR & NR & NR & NR & NR & $2 / 47 / 3$ & $22 \mathrm{C} 3$ & 22 & 27 & 15 & 19 & Primary tumor & Cytologic specimens & FNA & $\mathrm{R}$ \\
\hline Xu et al. (2018) & USA & 52 & NR & NR & NR & NR & NR & NR & 29/23/0 & $22 \mathrm{C} 3$ & 35 & 29 & NR & NR & Primary tumor & Cytologic specimens & $\begin{array}{c}\text { EBUS-TBNA/CT- } \\
\text { TBNA }\end{array}$ & $\mathrm{R}$ \\
\hline $\begin{array}{l}\text { Russell-Goldman } \\
\text { et al. (2018) }\end{array}$ & USA & 46 & 67.5 [42-90] & $13 / 33$ & NR & NR & NR & NR & $3 / 36 / 7$ & Other & 49 & 28 & 13 & 14 & Primary tumor & Cytologic specimens & FNA & $\mathrm{R}$ \\
\hline Li et al. (2017) & China & 190 & $56[34-78]$ & $134 / 56$ & 53 & 43 & 78 & 16 & $74 / 96 / 0$ & $22 \mathrm{C} 3$ & 63 & 70 & 21 & 26 & Primary tumor & Tissue microarrays & NR & $\mathrm{R}$ \\
\hline Sakata et al. (2018) & USA & 61 & $68[33-84]$ & $30 / 31$ & 2 & 17 & 41 & 1 & $21 / 39 / 1$ & $22 \mathrm{C} 3$ & 21 & 29 & 10 & 15 & Primary tumor & Histological specimens & EBUS-TBNA & $\mathrm{R}$ \\
\hline $\begin{array}{l}\text { Gradecki et al. } \\
\text { (2018) }\end{array}$ & USA & 51 & $65.5[37-86]$ & NR & NR & NR & NR & NR & $21 / 25 / 5$ & SP142 & 24 & 30 & 8 & 8 & Primary tumor & Histological specimens & NR & $\mathrm{R}$ \\
\hline Elfving et al. (2019) & Sweden & 58 & $61[40-82]$ & $26 / 32$ & NR & NR & NR & NR & $17 / 37 / 4$ & SP263 & 52 & 56 & 18 & 22 & Primary tumor & $\begin{array}{l}\text { Histological specimens/ } \\
\text { tissue microarrays }\end{array}$ & NR & $\mathrm{R}$ \\
\hline Kim et al. (2019) & Korea & 46 & $69[64-73]$ & $35 / 11$ & 18 & 18 & 10 & 0 & 24/20/2 & $\begin{array}{l}\text { 22C3/SP142/ } \\
\text { SP263 }\end{array}$ & 52 & 56 & 29 & 35 & Primary tumor & Histological specimens & $\begin{array}{c}\text { EBUS-TBNA/CT- } \\
\text { TBNA }\end{array}$ & $\mathrm{R}$ \\
\hline $\begin{array}{l}\text { Kitazono et al. } \\
\text { (2015) }\end{array}$ & Japan & 79 & 68 [38-83] & $50 / 28$ & 38 & 18 & 23 & 0 & $23 / 44 / 11$ & Other & 30 & 28 & 8 & 17 & Primary tumor & Histological specimens & NR & $\mathrm{R}$ \\
\hline
\end{tabular}

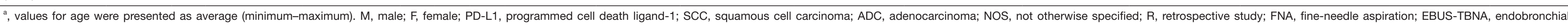
ultrasound-transbronchial needle aspiration; CT-TBNA, CT-guided transbronchial needle aspiration biopsy; TBLB, transbronchial lung biopsy; NR, not report. 


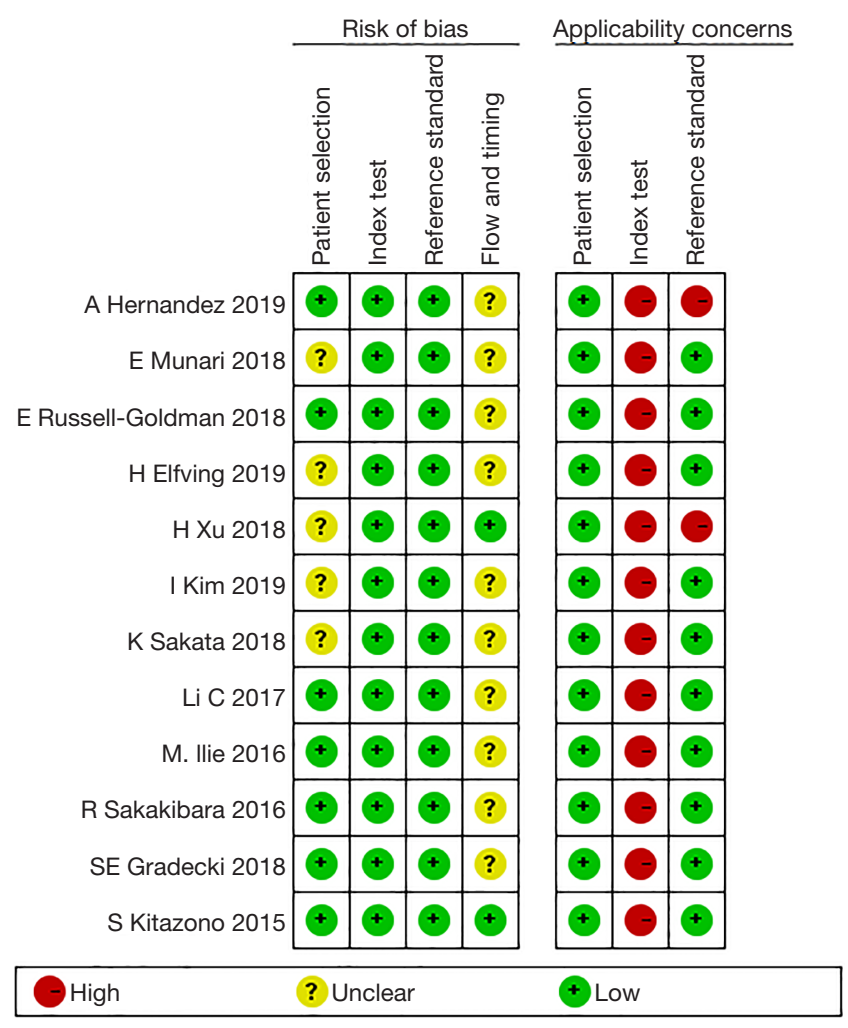

Figure 2 The risk of bias of included studies.

age data were available, only one study had an average age of less than 60 years old and immunostaining was conducted on tumor specimens mainly using the $22 \mathrm{C} 3$ or the SP142 or SP263 antibody clones. Only five original studies reported the complete staging information. Surgical resection specimens of all studies were primary tumors except for the study of Sakakibara et al. Modalities for biopsy specimens include fine-needle aspiration (FNA), endobronchial ultrasound-transbronchial needle aspiration (EBUSTBNA), CT-guided transbronchial needle aspiration biopsy (CT-TBNA), and transbronchial lung biopsy (TBLB). In addition, all researches were retrospective cohort studies and published between 2015 and 2019. Overall, the quality of all the original studies was similar based on the QUADAS-2 evaluation standard (Figure 2).

\section{PD-L1 $\geq 1 \%$ Cutoff}

At a PD-L1 IHC staining cutoff of $\geq 1 \%, 11$ original studies were evaluated and heterogeneity was identified in these included researches $\left(\mathrm{P}<0.01, \mathrm{I}^{2}=85 \%\right)$. The meta-analysis indicated that there was not a significant difference in the detection rate of PD-L1 at the $1 \%$ cutoff between biopsy specimens and surgical resection specimens ( $R R=0.89,95 \%$ CI: 0.70-1.12, $\mathrm{P}=0.33$; Figure 3).

\section{$P D-L 1 \geq 50 \%$ Cutoff}

In regard to the PD-L1 IHC staining cutoff of $\geq 50 \%, 10$ original studies were included in the analysis. Compared to surgical resection specimens, biopsy specimens experienced significantly higher detection value for PD-L1 expression ( $\mathrm{RR}=0.69,95 \%$ CI: $0.58-0.83, \mathrm{P}<0.01$ ), without evidence of heterogeneity ( $\mathrm{P}=0.56, \mathrm{I}^{2}=0 \%$; Figure 4$)$.

\section{Subgroup analysis}

Subgroup analysis was performed for the PD-L1 qualitative IHC assays and the type of biopsy specimens (Table 2). When compared with other PD-L1 qualitative IHC assays, the expression of PD-L1 in tumor cells detected by SP142 antibody was significantly reduced ( $1 \%$ cutoff, $\mathrm{RR}=0.48$, 95\% CI: $0.39-0.59, \mathrm{P}<0.01 ; 50 \%$ cutoff, $\mathrm{RR}=0.53,95 \% \mathrm{CI}$ : $0.38-0.75, \mathrm{P}<0.01)$. In regard to the type of specimens used in detection for PD-L1 expression, the value of histological specimens is lower than that of surgical resection specimens ( $1 \%$ cutoff, RR $=0.75,95 \%$ CI: $0.67-0.84, \mathrm{P}<0.01 ; 50 \%$ cutoff, RR $=0.64,95 \%$ CI: $0.51-0.80, \mathrm{P}<0.01$ ).

\section{Publication bias}

Funnel plots of the original study results showed that multiple points were evenly distributed on both sides of the longitudinal axis, so there was no obvious publication bias, which was further identified by the Egger's test (1\% cutoff, $\mathrm{P}=0.580$, Figure $5 ; 50 \%$ cutoff, $\mathrm{P}=0.509$, Figure 6).

\section{Discussion}

This meta-analysis of 12 original studies including 877 patients indicated that there was no significant difference in the detection rate of PD-L1 at the $1 \%$ cutoff between biopsy specimens and surgical resection specimens. However, there was a significant difference between the two groups when the cutoff is $50 \%$. In addition, a subgroup analysis of the type of biopsy specimens and the PD-L1 qualitative IHC assays showed that the detection rate of PD-L1 in small biopsies and using the SP142 antibody were lower than in surgical specimens and using other antibodies for both the $1 \%$ and $50 \%$ cut-offs. 


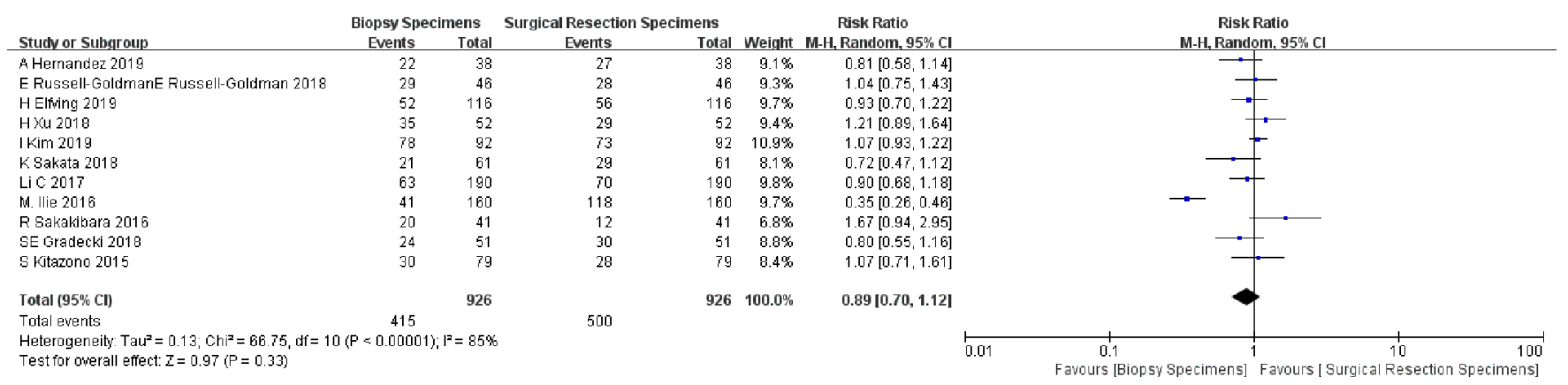

Figure 3 Meta-analysis: the detection rate of PD-L1 at the 1\% cutoff between biopsy specimens and surgical resection specimens. PD-L1, programmed cell death ligand-1.

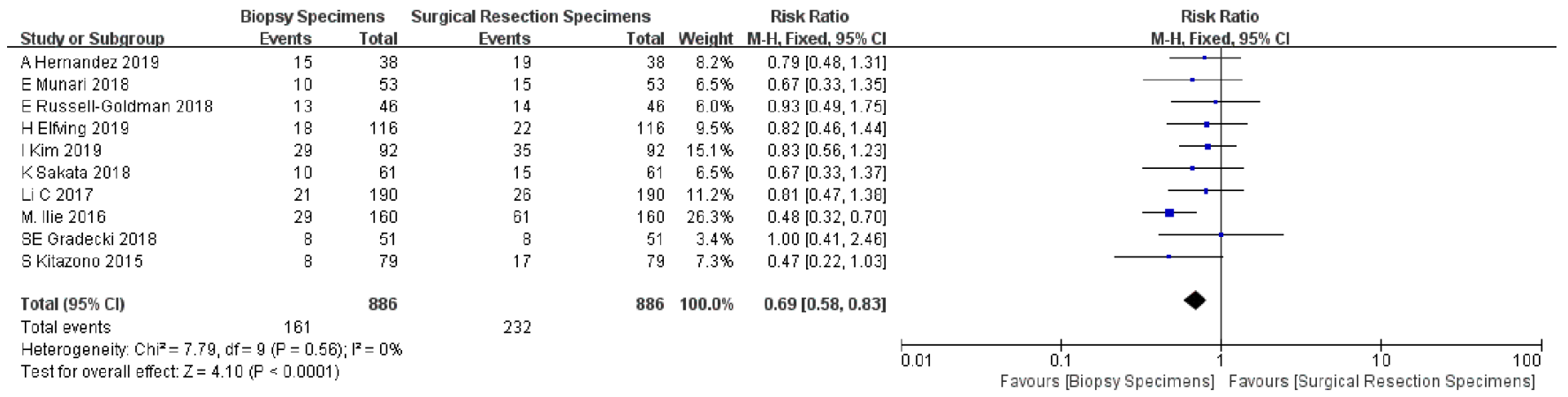

Figure 4 Meta-analysis: the detection rate of PD-L1 at the 50\% cutoff between biopsy specimens and surgical resection specimens. PD-L1, programmed cell death ligand-1.

Table 2 Subgroup analyses for PD-L1 $\geq 1 \%$ Cutoff and PD-L1 $\geq 50 \%$ Cutoff

\begin{tabular}{|c|c|c|}
\hline \multirow[t]{2}{*}{ Subgroups } & \multicolumn{2}{|c|}{$\begin{array}{c}\text { Combined relative risk }(95 \% \mathrm{Cl}) \text {, No. of } \\
\text { studies }\end{array}$} \\
\hline & PD-L1 $\geq 1 \%$ Cutoff & PD-L1 $\geq 50 \%$ Cutoff \\
\hline PD-L1 IHC assays & 0.78 (0.71-0.86), 10 & $0.70(0.58-0.84), 10$ \\
\hline SP263 & 0.98 (0.83-1.15), 2 & 0.79 (0.56-1.10), 3 \\
\hline $22 \mathrm{C3}$ & $0.93(0.80-1.07), 5$ & 0.79 (0.59-1.06), 4 \\
\hline SP142 & 0.48 (0.39-0.59), 3 & $0.53(0.38-0.75), 3$ \\
\hline $\begin{array}{l}\text { Type of biopsy } \\
\text { specimens }\end{array}$ & $0.83(0.76-0.91), 12$ & $0.69(0.58-0.83), 11$ \\
\hline $\begin{array}{l}\text { Histological } \\
\text { specimens }\end{array}$ & 0.75 (0.67-0.84), 7 & 0.64 (0.51-0.80), 6 \\
\hline Tissue microarrays & 0.92 (0.73-1.15), 2 & 0.78 (0.50-1.23), 2 \\
\hline $\begin{array}{l}\text { Cytologic } \\
\text { specimens }\end{array}$ & 1.02 (0.85-1.23), 3 & $0.79(0.56-1.12), 3$ \\
\hline
\end{tabular}

PD-L1, programmed cell death ligand-1.

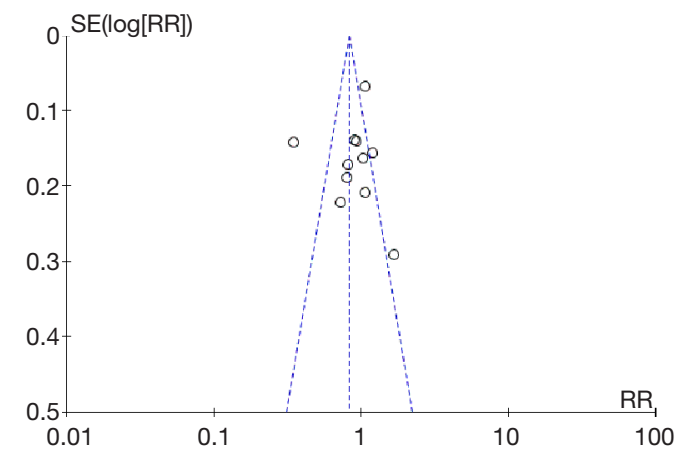

Figure 5 The funnel plot and publication bias tests for the detection rate of PD-L1 at the $1 \%$ cutoff between biopsy specimens and surgical resection specimens. PD-L1, programmed cell death ligand-1. 


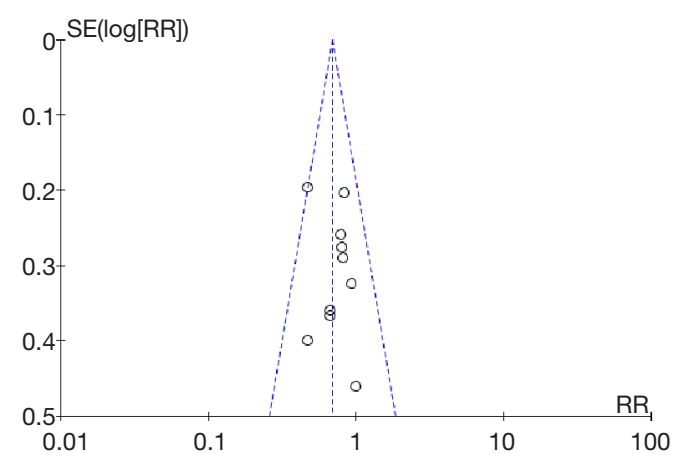

Figure 6 The funnel plot and publication bias tests for the detection rate of PD-L1 at the 50\% cutoff between biopsy specimens and surgical resection specimens. PD-L1, programmed cell death ligand-1.

The treatment landscape for patients with NSCLC has dramatically changed after the discovery of immune checkpoint inhibitors, including PD-1 and PD-L1 inhibitors. The results of PD-L1 expression detection are of great significance for clinicians to formulate treatment plans and predict therapeutic efficacy, especially for clinical medication guidance of Pembrolizumab. Based on the current studies, Pembrolizumab is recommended for firstline treatment in advanced NSCLC patients with high PD-L1 expression (tumors showing $\geq 50 \%$ tumoral staining for PD-L1) and for second-line treatment in patients with advanced NSCLC who have received one or more previous treatment regimen and who have a tumor proportion score of at least $1 \%(6,8)$. The main outcome of the meta-analysis showed that when the threshold value was $1 \%$ or $50 \%$, the detection value of the surgically resected specimen was higher than that of the biopsy specimen, and there was a significant difference in the latter. Therefore, in the selection of patients suitable for first-line treatment (tumor proportion score of at least $50 \%$ ), multiple biopsy specimens may be needed to avoid the occurrence of false detection results and allow clinicians to make a more confident decision with regard to patient selection for therapy. Munari et al. reported in 2017 that caution must be taken when using biopsy specimens to assess immunotreatment-eligible patients with advanced NSCLC, requiring at least 4 biopsy specimens to minimize the risk of error (15). Then in 2018, Munari et al. compared the detection value of PD-L1 expression in 39 biopsy specimens and surgical resection specimens and found that four and three biopsy specimens had the highest accuracy in detecting PD-L1 expression when the threshold value was $1 \%$ and $50 \%$ respectively (32).
For each PD-1/PD-L1 inhibitor, a specific PD-L1 qualitative IHC assay was developed to assess PD-L1 expression levels on malignant NSCLC tumor cells and/ or immune cells. They are not necessary for treatment but may support clinical decision-making. In order to analyze the influence of common PD-L1 monoclonal antibodies on the detection of PD-L1 expression in biopsies specimens and surgical resection specimens, we excluded two clinically infrequently used PD-L1 monoclonal antibodies and performed subgroup analysis on the antibodies used in the remaining studies. The results showed that compared to the SP263 IHC and the 22C3 IHC assays, the SP242 IHC assay resulted in an underestimation of PD-L1 expression in tumor cells. The findings are not surprising since each assay was developed and optimized as predictive biomarker for a specific antibody. The National Comprehensive Cancer Network analyzed 90 resected NSCLC tumor specimens stained using four PD-L1 IHC assays (28-8, 22C3, SP142, and E1L3N). Their results also showed that the SP142 assay detected lower PD-L1 expression levels on tumor and immune cells than the other assays (33). The overall concordance among the four assays was excellent $(\mathrm{k}=0.813)$, and was even higher if SP142 was excluded $(\mathrm{k}=0.971)$ (33). In addition, Hendry et al. obtained similar results as ours by comparing the effects of different PD-L1 monoclonal antibodies on IHC results (34). Judging from their studies, all assays detected tumor cells but to a different extent, probably confounded by pathologist variability in the overall scores for tumor cells across the assays. Since the purpose of our study is not to explore the differences among these antibodies, more clinical evidence is needed to prove this hypothesis.

Different types of biopsy specimens may have different IHC test results, so this study conducted a subgroup analysis on the types of biopsy specimens. Based on the experimental indicators, this present meta-analysis compared the surgical resection specimens with the histological specimens (9). However, not all patients with NSCLC have access to histological specimens; In more than $30 \%$ of patients, only cytological specimens obtained by fine needle aspiration (FNA) are available. In clinical practice, cytological specimens serve as the only diagnostic material available for PD-L1 expression in approximately $16 \%$ of patients. Metaanalysis indicated that histological specimens had a lower detection values than cytological specimens. However, Noll et al. reached a conclusion contrary to ours by comparing the value of detecting PD-L1 expression in tumor cells of cytological samples and histological samples from 41 NSCLC patients. They believed that the cytological 
samples used for detecting PD-L1 expression in NSCLC patients were highly consistent with histological samples and could be used to evaluate PD-L1 expression (35).

To best of our knowledge, this is the first study comparing the detection value of biopsy specimens and surgical resection specimens for PD-L1 expression in patients with NSCLC. By expanding the influencing factors and results of PD-L1 expression detection in tumor cells, a comprehensive subgroup analysis was conducted to carefully analyze the potential confounding factors, and it was confirmed that the PD-L1 qualitative IHC assays and the type of biopsy specimens were the possible factors leading to the difference in PD-L1 expression between biopsy specimens and surgical resection specimens in NSCLC patients.

Our meta-analysis had several limitations that must be considered. One major limitation of this meta-analysis is that all included researches were retrospective cohort studies which have a certain inevitable bias. We evaluated the quality of 12 original studies based on the QUADAS-2 evaluation standard and judged most included studies at high quality. Although the funnel plot and bias test of major outcome did not indicate evident publication bias among included studies, it is necessary to wait for more results from RCT to draw a valid conclusion.

\section{Conclusions}

Current evidence suggests that caution must be taken when using biopsy specimens from patients with advanced NSCLC to evaluate PD-L1 status eligible for immunotherapy, additional biopsy specimens sampling may be needed in order to minimize the risk of tumor misclassification. In addition, PD-L1 qualitative IHC assays and the type of biopsy specimens related to PD-L1 expression detection.

\section{Acknowledgments}

Funding: This study was supported by Clinical Research Foundation of Shanghai Pulmonary Hospital (FK1943, FK1936, FK1942, FK1941), Shanghai Municipal Health Commission (2018ZHYL0102, 2019SY072), Medicine and Public Health Scientific Projects in Zhejiang Province (2020KY270) and Huamei Key Research Foundation (2019HMZD05).

\section{Footnote}

Reporting Checklist: The authors have completed the
PRISMA reporting checklist. Available at https://dx.doi. org/10.21037/jtd-21-543

Conflicts of Interest: All authors have completed the ICMJE uniform disclosure form (available at https://dx.doi. org/10.21037/jtd-21-543). The authors have no conflicts of interest to declare.

Ethical Statement: The authors are accountable for all aspects of the work in ensuring that questions related to the accuracy or integrity of any part of the work are appropriately investigated and resolved.

Open Access Statement: This is an Open Access article distributed in accordance with the Creative Commons Attribution-NonCommercial-NoDerivs 4.0 International License (CC BY-NC-ND 4.0), which permits the noncommercial replication and distribution of the article with the strict proviso that no changes or edits are made and the original work is properly cited (including links to both the formal publication through the relevant DOI and the license). See: https://creativecommons.org/licenses/by-nc-nd/4.0/.

\section{References}

1. Miller KD, Nogueira L, Mariotto AB, et al. Cancer treatment and survivorship statistics, 2019. CA Cancer J Clin 2019;69:363-85.

2. Sung H, Ferlay J, Siegel RL, et al. Global Cancer Statistics 2020: GLOBOCAN Estimates of Incidence and Mortality Worldwide for 36 Cancers in 185 Countries. CA Cancer J Clin 2021;71:209-49.

3. Brahmer JR, Pardoll DM. Immune checkpoint inhibitors: making immunotherapy a reality for the treatment of lung cancer. Cancer Immunol Res 2013;1:85-91.

4. Borghaei H, Paz-Ares L, Horn L, et al. Nivolumab versus Docetaxel in Advanced Nonsquamous Non-Small-Cell Lung Cancer. N Engl J Med 2015;373:1627-39.

5. Brahmer J, Reckamp KL, Baas P, et al. Nivolumab versus Docetaxel in Advanced Squamous-Cell Non-Small-Cell Lung Cancer. N Engl J Med 2015;373:123-35.

6. Herbst RS, Baas P, Kim DW, et al. Pembrolizumab versus docetaxel for previously treated, PD-L1-positive, advanced non-small-cell lung cancer (KEYNOTE-010): a randomised controlled trial. Lancet 2016;387:1540-50.

7. Langer CJ, Gadgeel SM, Borghaei H, et al. Carboplatin and pemetrexed with or without pembrolizumab for advanced, non-squamous non-small-cell lung cancer: 
a randomised, phase 2 cohort of the open-label KEYNOTE-021 study. Lancet Oncol 2016;17:1497-508.

8. Reck M, Rodríguez-Abreu D, Robinson AG, et al. Pembrolizumab versus Chemotherapy for PD-L1Positive Non-Small-Cell Lung Cancer. N Engl J Med 2016;375:1823-33.

9. Garon EB, Rizvi NA, Hui R, et al. Pembrolizumab for the treatment of non-small-cell lung cancer. N Engl J Med 2015;372:2018-28.

10. Topalian SL, Hodi FS, Brahmer JR, et al. Safety, activity, and immune correlates of anti-PD-1 antibody in cancer. $\mathrm{N}$ Engl J Med 2012;366:2443-54.

11. Topalian SL, Sznol M, McDermott DF, et al. Survival, durable tumor remission, and long-term safety in patients with advanced melanoma receiving nivolumab. J Clin Oncol 2014;32:1020-30.

12. Taube JM, Klein A, Brahmer JR, et al. Association of PD1, PD-1 ligands, and other features of the tumor immune microenvironment with response to anti-PD-1 therapy. Clin Cancer Res 2014;20:5064-74.

13. Rittmeyer A, Barlesi F, Waterkamp D, et al. Atezolizumab versus docetaxel in patients with previously treated non-small-cell lung cancer (OAK): a phase 3, openlabel, multicentre randomised controlled trial. Lancet 2017;389:255-65.

14. Yearley JH, Gibson C, Yu N, et al. PD-L2 Expression in Human Tumors: Relevance to Anti-PD-1 Therapy in Cancer. Clin Cancer Res 2017;23:3158-67.

15. Munari E, Zamboni G, Marconi M, et al. PD-L1 expression heterogeneity in non-small cell lung cancer: evaluation of small biopsies reliability. Oncotarget 2017;8:90123-31.

16. Ilie M, Long-Mira E, Bence C, et al. Comparative study of the PD-L1 status between surgically resected specimens and matched biopsies of NSCLC patients reveal major discordances: a potential issue for anti-PD-L1 therapeutic strategies. Ann Oncol 2016;27:147-53.

17. Li C, Huang C, Mok TS, et al. Comparison of 22C3 PDL1 Expression between Surgically Resected Specimens and Paired Tissue Microarrays in Non-Small Cell Lung Cancer. J Thorac Oncol 2017;12:1536-43.

18. Munari E, Zamboni G, Sighele G, et al. Expression of programmed cell death ligand 1 in non-small cell lung cancer: Comparison between cytologic smears, core biopsies, and whole sections using the SP263 assay. Cancer Cytopathol 2019;127:52-61.

19. Hernandez A, Brandler TC, Zhou F, et al. Assessment of Programmed Death-Ligand 1 (PD-L1)
Immunohistochemical Expression on Cytology Specimens in Non-Small Cell Lung Carcinoma. Am J Clin Pathol 2019;151:403-15.

20. Knobloch K, Yoon U, Vogt PM. Preferred reporting items for systematic reviews and meta-analyses (PRISMA) statement and publication bias. J Craniomaxillofac Surg 2011;39:91-2.

21. Whiting PF, Rutjes AW, Westwood ME, et al. QUADAS-2: a revised tool for the quality assessment of diagnostic accuracy studies. Ann Intern Med 2011;155:529-36.

22. Higgins JP, Thompson SG. Quantifying heterogeneity in a meta-analysis. Stat Med 2002;21:1539-58.

23. Egger M, Davey Smith G, Schneider M, et al. Bias in meta-analysis detected by a simple, graphical test. BMJ 1997;315:629-34.

24. Kitazono S, Fujiwara Y, Tsuta K, et al. Reliability of Small Biopsy Samples Compared With Resected Specimens for the Determination of Programmed Death-Ligand 1 Expression in Non--Small-Cell Lung Cancer. Clin Lung Cancer 2015;16:385-90.

25. Sakakibara R, Inamura K, Tambo $Y$, et al. EBUS-TBNA as a Promising Method for the Evaluation of Tumor PD-L1 Expression in Lung Cancer. Clin Lung Cancer 2017;18:527-534.e1.

26. Sakata KK, Midthun DE, Mullon JJ, et al. Comparison of Programmed Death Ligand-1 Immunohistochemical Staining Between Endobronchial Ultrasound Transbronchial Needle Aspiration and Resected Lung Cancer Specimens. Chest 2018;154:827-37.

27. Xu H, Bratton L, Nead M, et al. Comparison of programmed death-ligand 1 (PD-L1) immunostain for nonsmall cell lung carcinoma between paired cytological and surgical specimens. Cytojournal 2018;15:29.

28. Russell-Goldman E, Kravets S, Dahlberg SE, et al. Cytologic-histologic correlation of programmed deathligand 1 immunohistochemistry in lung carcinomas. Cancer Cytopathol 2018;126:253-63.

29. Gradecki SE, Grange JS, Stelow EB. Concordance of PD-L1 Expression Between Core Biopsy and Resection Specimens of Non-Small Cell Lung Cancer. Am J Surg Pathol 2018;42:1090-4.

30. Elfving H, Mattsson JSM, Lindskog C, et al. Programmed Cell Death Ligand 1 Immunohistochemistry: A Concordance Study Between Surgical Specimen, Biopsy, and Tissue Microarray. Clin Lung Cancer 2019;20:258-262.e1.

31. Kim I, Kim A, Lee CH, et al. Reliability of PD-L1 
assays using small tissue samples compared with surgical specimens. Medicine (Baltimore) 2019;98:e14972.

32. Munari E, Zamboni G, Lunardi G, et al. PD-L1

Expression Heterogeneity in Non-Small Cell Lung Cancer: Defining Criteria for Harmonization between Biopsy Specimens and Whole Sections. J Thorac Oncol 2018;13:1113-20.

33. Rimm DL, Han G, Taube JM, et al. A Prospective, Multi-institutional, Pathologist-Based Assessment of 4

Cite this article as: Wang $\mathrm{Y}, \mathrm{Wu} \mathrm{J}$, Deng J, She Y, Chen C. The detection value of PD-L1 expression in biopsy specimens and surgical resection specimens in non-small cell lung cancer: a meta-analysis. J Thorac Dis 2021;13(7):4301-4310. doi: 10.21037/ jtd-21-543
Immunohistochemistry Assays for PD-L1 Expression in Non-Small Cell Lung Cancer. JAMA Oncol 2017;3:1051-8.

34. Hendry S, Byrne DJ, Wright GM, et al. Comparison of Four PD-L1 Immunohistochemical Assays in Lung Cancer. J Thorac Oncol 2018;13:367-76.

35. Noll B, Wang WL, Gong Y, et al. Programmed death ligand 1 testing in non-small cell lung carcinoma cytology cell block and aspirate smear preparations. Cancer Cytopathol 2018;126:342-52. 